\title{
Design of Small Photovoltaic Power Generation System Based on Maximum Power Point Tracking
}

\author{
Yang Cui ${ }^{[1]}$, Cheng Liu ${ }^{[1 *]}$, Yanming Cheng ${ }^{[1]}$, Jing Niu ${ }^{[2]}$ \\ ${ }^{[1]}$ College of Electrical \& Information Engineering, BeiHua University, Jilin, 132012, China \\ ${ }^{[2]}$ Jilin Chemical Fiber Group Co., Ltd., Jilin, 132021, China \\ *Corresponging author: Cheng Liu, Email:bhdqxy@163.com
}

\begin{abstract}
According to the nonlinear output characteristics of photovoltaic cells, combined with artificial intelligence algorithmthe the MPPT (Maximum Power Point Tracking) control algorithm based on fuzzy variable step size is proposed, which enables the system to quickly track the maximum power point and improve the energy conversion efficiency of photovoltaic system. This paper designs a small-scale photovoltaic power generation system. The main circuit of the system consists of Perovskite Solar Panels, DC voltage regulator circuit, storage battery and one-way full bridge inverter circuit. The control circuit consists of sun-seeking, inverter and maximum power tracking on constant voltage. Proteus simulation software is used to simulate the sun-seeking part, the inverting part, the general control unit, the keys and the display interface. The results indicate that the functions of the small-scale photovoltaic power generation system can be achieved very well.
\end{abstract}

Keywords: Photovoltaic power, Fuzzy variable step algorithm, Sun-seeking; MPPT; Inverter

\section{Introduction}

Photovoltaic technology started earlier in foreign countries. Germany, the United States and India are relatively leading in photovoltaic power generation technology. They are also the first countries to study photovoltaic power generation. Meyer burger Technology Ag will transform itself into a leading manufacturer of solar cells and components. It is expected to be officially put into production in the first half of 2021 , and it is planned to increase the capacity of batteries and components to $1.4 \mathrm{GW}$ and $0.8 \mathrm{GW}$ respectively by 2022 . China's development is also relatively rapid. Large photovoltaic power stations have been built in places with sufficient light, such as Xinjiang and Tibet [1]. Since the electric energy generated by solar cells always changes with the change of solar cell temperature and irradiance, it is necessary to track the maximum power point of photovoltaic system effectively[2].At present, there are many MPPT methods, such as disturbance and observation algorithm[3-5], conductance increment algorithm[6-7], neural network method[8-10] and fuzzy logic algorithm[11-15].This type of control mode may have a series of effects, including large scale delay, more inaccurate detection circuits and sensors, and power oscillations under low radiation conditions. According to the nonlinear output characteristics of photovoltaic cells, the MPPT control algorithm based on fuzzy variable step size is proposed, which enables the system to quickly track the maximum power point and improve the energy conversion efficiency of photovoltaic system.

This paper designs a small photovoltaic power generation system, including the main circuit and control part of the system, and Proteus simulation software is used for simulation. Finally, the DC part is stabilized at $48 \mathrm{~V}$, and the inverter part forms an approximate SPWM waveform, and the sun-seeking part makes the solar panel automatically track the rotation of light intensity. 


\section{Brief introduction of system scheme}

\subsection{Main circuit system structure}

The system structure is shown in Figure 1. Through DC/DC conversion circuit, the system outputs the electric energy of solar panel to $220 \mathrm{~V}$ users through constant pressure control and DC/AC inverter. In addition, the electricity generated by the solar panel is stored in the battery group in real time, when there is no sunlight, the battery discharge guarantees the reliability of power supply.

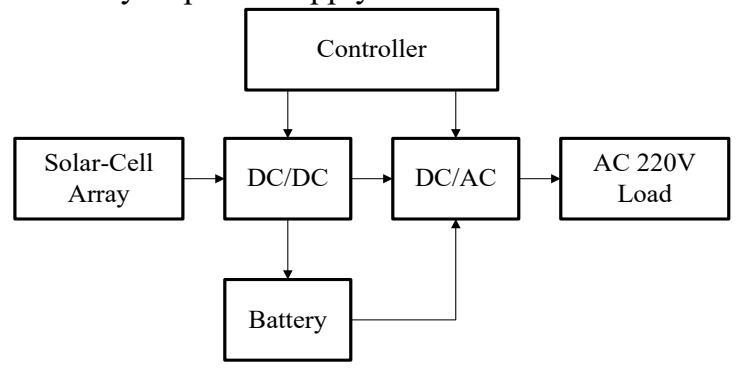

Figure 1: Structural block diagram of main circuit system

\subsection{Structure design of control system}

The control system structure is shown in Figure 2. The system is composed of sun tracing unit, inverter unit (DC/AC) and general control unit (including DC/DC). The functions of each part are as follows:

Sun-seeking unit: Solar panel lighting angle control;

Inverter unit: Power generation inverter control;

Overall control unit: The main control unit of the system completes the DC/DC maximum power tracking control, the general control of the sun-seeking unit and inverter unit.

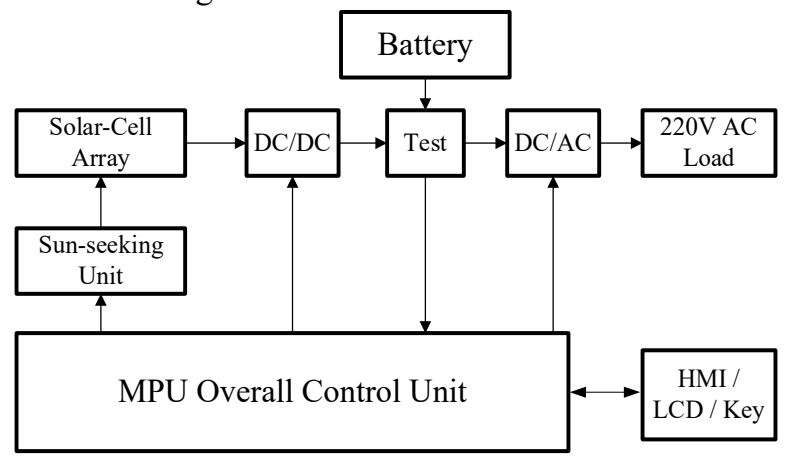

Figure 2: Structure block diagram of control system

\subsection{Parameter calculation of battery and solar panel}

A.Selection of battery capacity

The power of the system is $2000 \mathrm{~W}$, in case of continuous rainy days or no light at night, the system battery is used to supply power for the system. The power of the system is $2000 \mathrm{~W}$, the working voltage is $48 \mathrm{~V}$, through the calculation formula of battery capacity, the capacity $\mathrm{C}$ of battery is $200 \mathrm{~A} \cdot \mathrm{H}$. The output voltage is $48 \mathrm{~V}$ and the nominal voltage of the battery is $6 \mathrm{~V}$, so 8 batteries need to be connected in series.

B.Selection of solar panel

In order to ensure the maximum power output of the solar panel, it is necessary to charge the battery. The working voltage of the battery is $48 \mathrm{~V}$, and the peak voltage of the solar panel is $48 \mathrm{~V}$, so that the solar panel can work at the maximum power point. The solar panel selected in this paper has a peak power of $250 \mathrm{~W}$, a peak voltage of $48.33 \mathrm{~V}$, a peak current of 5.18A, an open circuit voltage of 57.08V and a short circuit current of 5.69A. Eight solar panels are connected in parallel, with a total power of $2000 \mathrm{~W}$. 


\section{MPPT control based on fuzzy variable step size}

MPPT (maximum power point tracking) technology is an important part of photovoltaic system. The operation of photovoltaic cells is closely related to the irradiance of the incident sunlight and the temperature of the external environment. The output characteristics of photovoltaic cells show typical nonlinear characteristics. In a certain light and temperature environment, the photovoltaic system output will only have a unique maximum power point. Therefore, we should always ensure that the output power of photovoltaic works in the optimal state, so as to maximize the conversion of solar energy into electrical energy.

\subsection{Classical MPPT control}

In the photovoltaic power generation system, the closed-loop control is mostly used to achieve the maximum power output control of photovoltaic cells. In this way, the current and voltage of photovoltaic are detected in real time, and the state of MPPT is determined by closed-loop calculation. At present, two classical MPPT algorithms are disturbance observation method and conductance increment method. With the development of intelligent control, there are fuzzy control method and neural network method.

The principle of MPPT charge control based on buck converter is shown in Figure $3 . U_{\mathrm{PV}}$ and $I_{\mathrm{PV}}$ are the output voltage and current of photovoltaic array, $U_{\mathrm{b}}$ and $I_{\mathrm{b}}$ are the voltage and current of battery respectively.

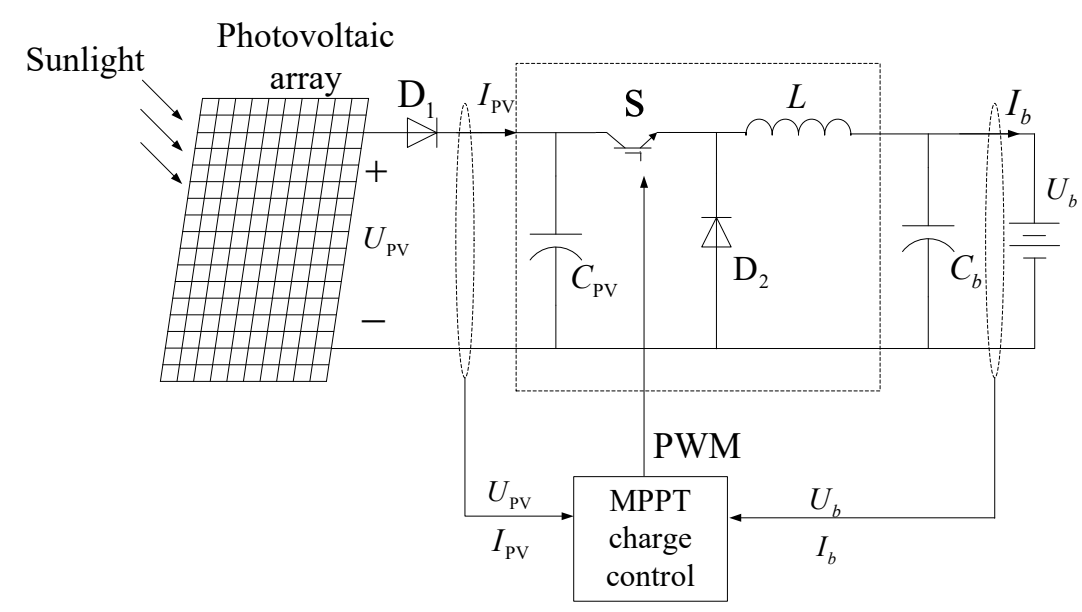

Figure 3: MPPT charge control schematic diagram based on Buck Converter

\subsection{MPPT control based on fuzzy variable step size}

The variable step size disturbance observation method is derived from the improvement of the conventional fixed step size disturbance observation method to make up for the contradiction between response and accuracy. When the deviation from the maximum power point is far, the large step tracking is used, and when the distance from the maximum power point is close, the small step tracking is used instead, so as to reduce the adjustment time. In this paper, the MPPT control of photovoltaic array is carried out by using the variable step size disturbance observation method, which does not need to be as strict as the conductance increment method for the accuracy of control system components.

The target function is the output power $P$ of the photovoltaic array, and the control quantity is the duty cycle $D$ of the PWM driving signal of the power switch of the buck converter. Take the fuzzy controller as the structure of two inputs and one output. One input is the power difference $e(n)=P(n)-P(n-1)$ between the current time and the previous time, and the other is the duty cycle step $a(n-1)$ of the previous time. One output is duty cycle step $a(n)$ at the current time. Therefore, the adjustment algorithm of duty cycle is $D(n)=D(n-1)+a(n)$.As shown in Figure 4 


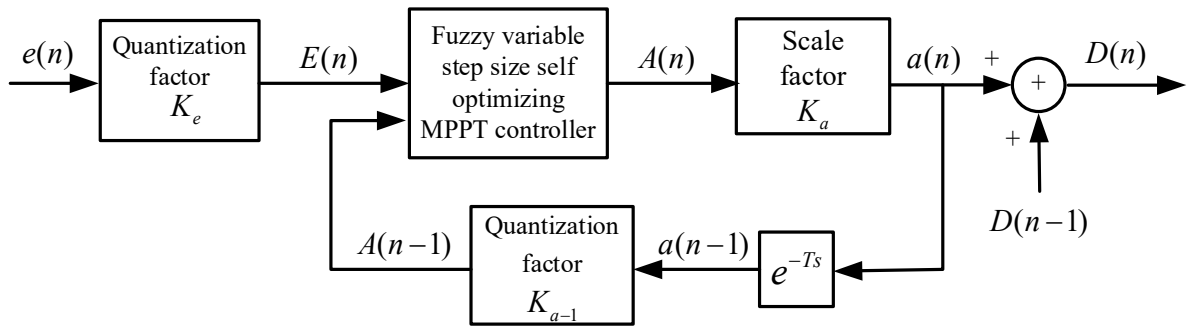

Figure 4: MPPT structure based on Fuzzy control

$E$ and $A$ are the fuzziness of $\mathrm{e}$ and $\mathrm{a}$ respectively. Here $\mathrm{E}$ is defined as 8 fuzzy subsets, $E=\{N B, N M, N S, N O, P O, P S, P M, P B\} \quad$.It $\quad$ is $\quad$ divided $\quad$ into $14 \quad$ levels, $E=\{-6,-5,-4,-3,-2,-1,-0,+0,+1,+2,+3,+4,+5,+6\} \quad$. And $\quad A \quad$ is defined as 6 fuzzy subsets, $\quad A=\{N B, N M, N S, P S, P M, P B\} \quad$. It $\quad$ is $\quad$ divided $\quad$ into $12 \quad$ levels, $A=\{-6,-5,-4,-3,-2,-1,+1,+2,+3,+4,+5,+6\}$.The membership function of the two are shown in Figure 5 .

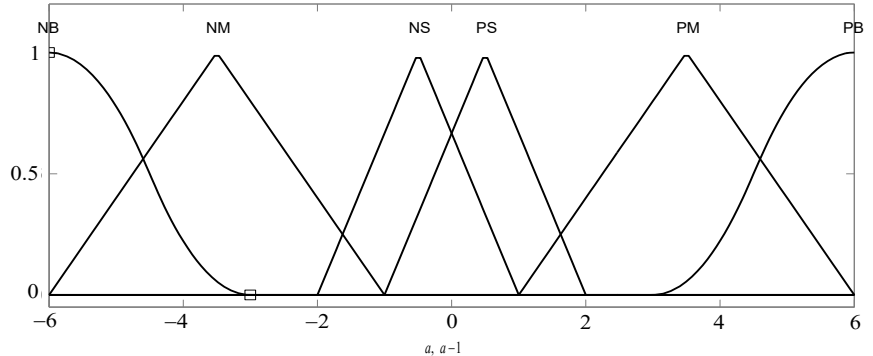

a. Membership function of step value A



b. Membership function of power variation $\mathrm{E}$

Figure 5: Membership function of fuzzy control

The adjustment step value of the current time duty ratio is determined according to the change of power value and the adjustment step value of the previous time duty ratio. According to the relationship between the P-U characteristic curve of photovoltaic array, and considering the influence of light intensity and temperature on the output power of photovoltaic array comprehensively, the adjustment principle is determined

Table 1 is a list of 48 fuzzy rules controlled by MPPT. The selection principle of fuzzy rule table is: 1) if the disturbance is in the same direction and the output power is increased, the disturbance will continue in the same direction, if there is a decrease, the disturbance will be adjusted in the opposite direction; 2) when the deviation from the maximum power point is far, the large step tracking is used, and when the distance from the maximum power point is close, the small step tracking is used, so as to reduce the adjustment time.

Table 1: MPPT fuzzy control rules 


\begin{tabular}{|c|c|c|c|c|c|c|c|c|}
\hline \multirow{3}{*}{$A(n-1)$} & \multicolumn{8}{|c|}{$E(n)$} \\
\hline & NB & NM & NS & NO & PO & PS & PM & PB \\
\hline & \multicolumn{8}{|c|}{$A(n)$} \\
\hline NB & PB & PM & PS & PS & NS & NS & NS & NM \\
\hline NM & PB & PB & PM & PS & NS & NS & NS & NM \\
\hline NS & PB & PB & PM & PS & NS & NS & NS & NS \\
\hline PS & NS & NS & NS & NS & PS & PM & PB & PB \\
\hline $\mathrm{PM}$ & $\mathrm{NM}$ & NS & NS & NS & PS & PM & PB & PB \\
\hline PB & NM & NS & NS & NS & PS & PS & PM & PB \\
\hline
\end{tabular}

In order to reduce the power oscillation at the maximum power point, when the power deviation is $|e|<0.1$, it means that the duty cycle of the disturbance will not cause much change in the output power. At this time, the power point is relatively close to the maximum power point. It can be considered that the power at this point is the maximum power point, and the disturbance will not be carried out at this time. Through this design, the power oscillation at the maximum power point can be effectively reduced.

\section{System hardware design}

\subsection{Power circuit design}

The power conversion circuit is shown in Figure 6. The output DC bus voltage of the battery is $48 \mathrm{~V}$, which is composed of eight $6 \mathrm{~V}$ battery cells. The working voltage of the DC motor is $24 \mathrm{~V}$, $(24 \mathrm{~V}$ obtains power from 4 battery cells in series). The control part of the system is powered by DC5V, so the DC $24 \mathrm{~V}-5 \mathrm{~V}$ conversion circuit needs to be designed. The voltage is directly powered by TPS5430DDA DC-DC Buck chip.



Figure 6: Power Circuit Design

\subsection{Sun-seeking unit design}

As shown in Figure 7. Light detection is realized by 4 photoresistors. In the amplification circuit, the detected light intensity is converted into voltage signal, and then read by single chip microcomputer after AD conversion. Finally, the running direction of stepping motor is adjusted by single chip microcomputer to achieve the purpose of changing the light intensity of solar energy. With the change of light intensity, the angle of stepper motor is adjusted to realize the rotation of $\mathrm{X}$ and $\mathrm{Y}$ directions, and finally realize the maximum intensity utilization of sunlight. 


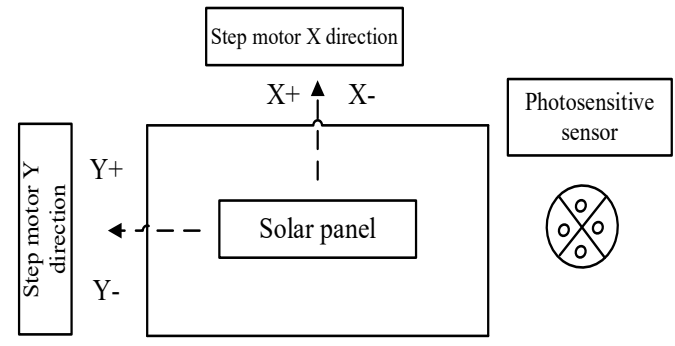

Figure 7: Sun-seeking control

\subsection{Inverter unit design}

The inverter main circuit is shown in Figure 8. The full bridge is realized by controlling 4 IGBT, and the DC-AC transformation is realized by the conduction of the cross bridge arm. In the circuit, D1, D2, D3 and D4 play the role of continuous current. Resistance R1, R2, R3, R4, capacitance C1, C2, C3, C4 constitute RC filter circuit to reduce the fluctuation of bridge arm switch. IGBT is controlled by single-chip microcomputer and then output SPWM waveform to the user through transformer TC901. In the circuit, KA901 is the output switch (Contactor).

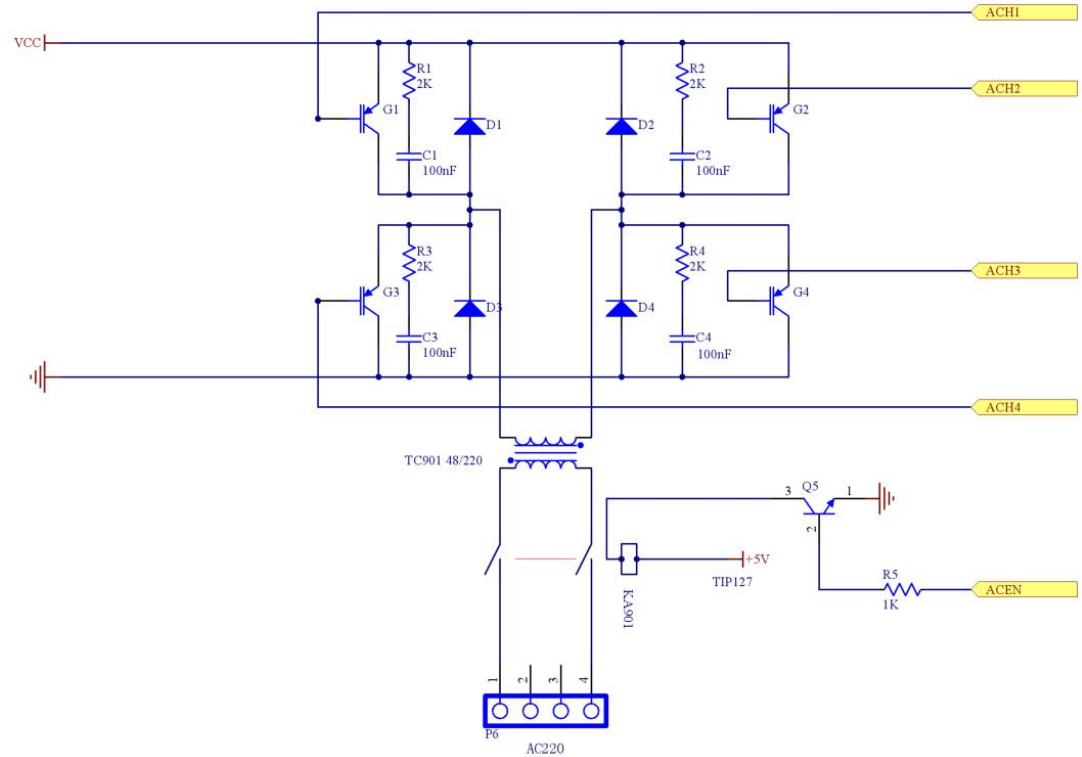

Figure 8: Design of inverter main circuit

\section{System software design}

\subsection{Program design of sun-seeking unit}

In this paper, the illuminance of the sun tracing part is designed to track between 45 and 55 degrees, and the flow chart of the sun tracing unit is shown in Figure 9. 


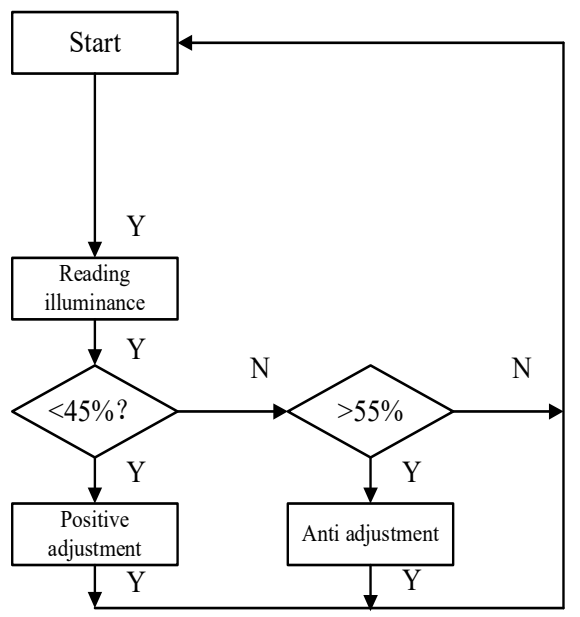

Figure 9: Sun-seeking adjustment flow chart

\subsection{Program design of inverter unit}

The control function of inverter unit is mainly realized by SPWM OUT function, and its workflow is shown in Figure 10 .

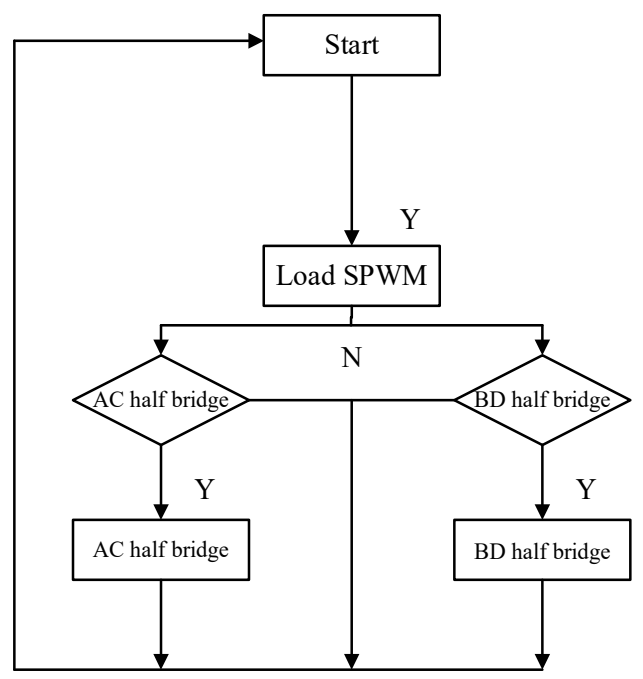

Figure 10: Inverter flow chart

\section{Results}

\subsection{Simulation and debugging of sun-seeking unit}

In this paper, proteus simulation software is used for simulation, and the circuit diagram is shown in Figure 11. U2 and $\mathrm{U} 3$ are analog-to-digital conversion in $\mathrm{X}$ direction and $\mathrm{Y}$ direction respectively. RV1 and RV2 simulate the change of photoresistance under different illumination levels. The control mode is enable and pulse plus direction (positive adjustment when DIR is 0). EN and ST simulate the signals from the general control unit of the system. 


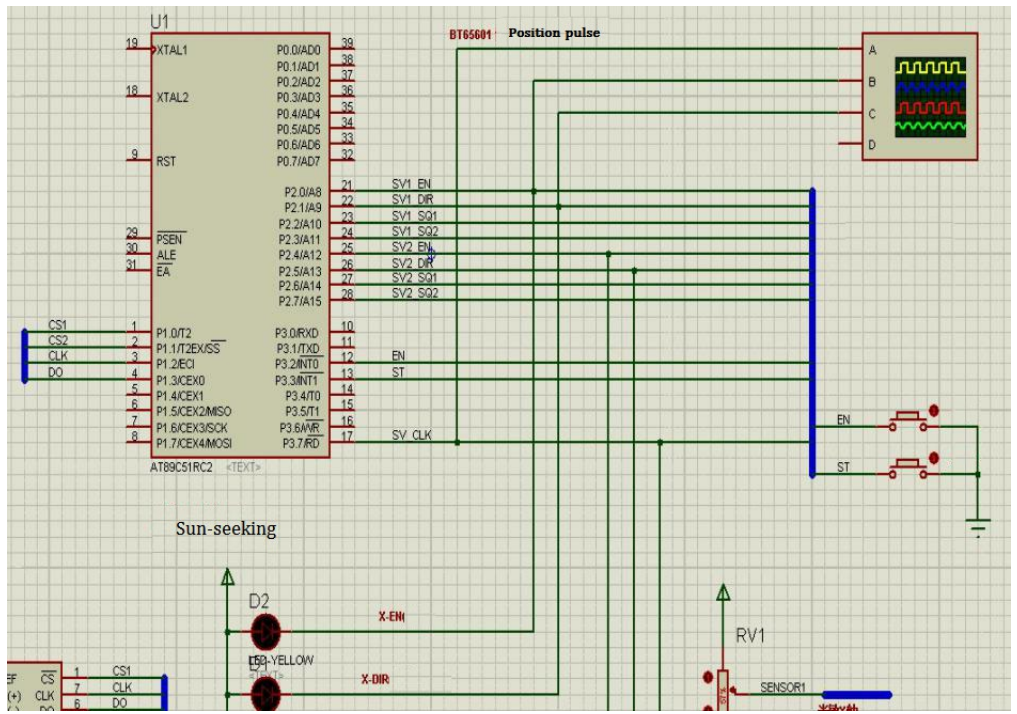

Figure 11: Sun-seeking simulation diagram

\subsection{Simulation and debugging of inverter unit}

The signal simulation diagram of the inverter part is shown in Figure 12. The AC contactor switch output by D1 analog transformer, EN and ST control enable and output respectively. In the oscilloscope, yellow is the AC half bridge (ach1 and ach3) of single-phase full bridge inverter circuit, and red is the BD half bridge (ach2 and ach4). When the main control ST has signal, D1 channel, inverter begins to output. When EN has a signal, the inverter starts to work, and the inverter output waveform is realized by IGBT on-off.

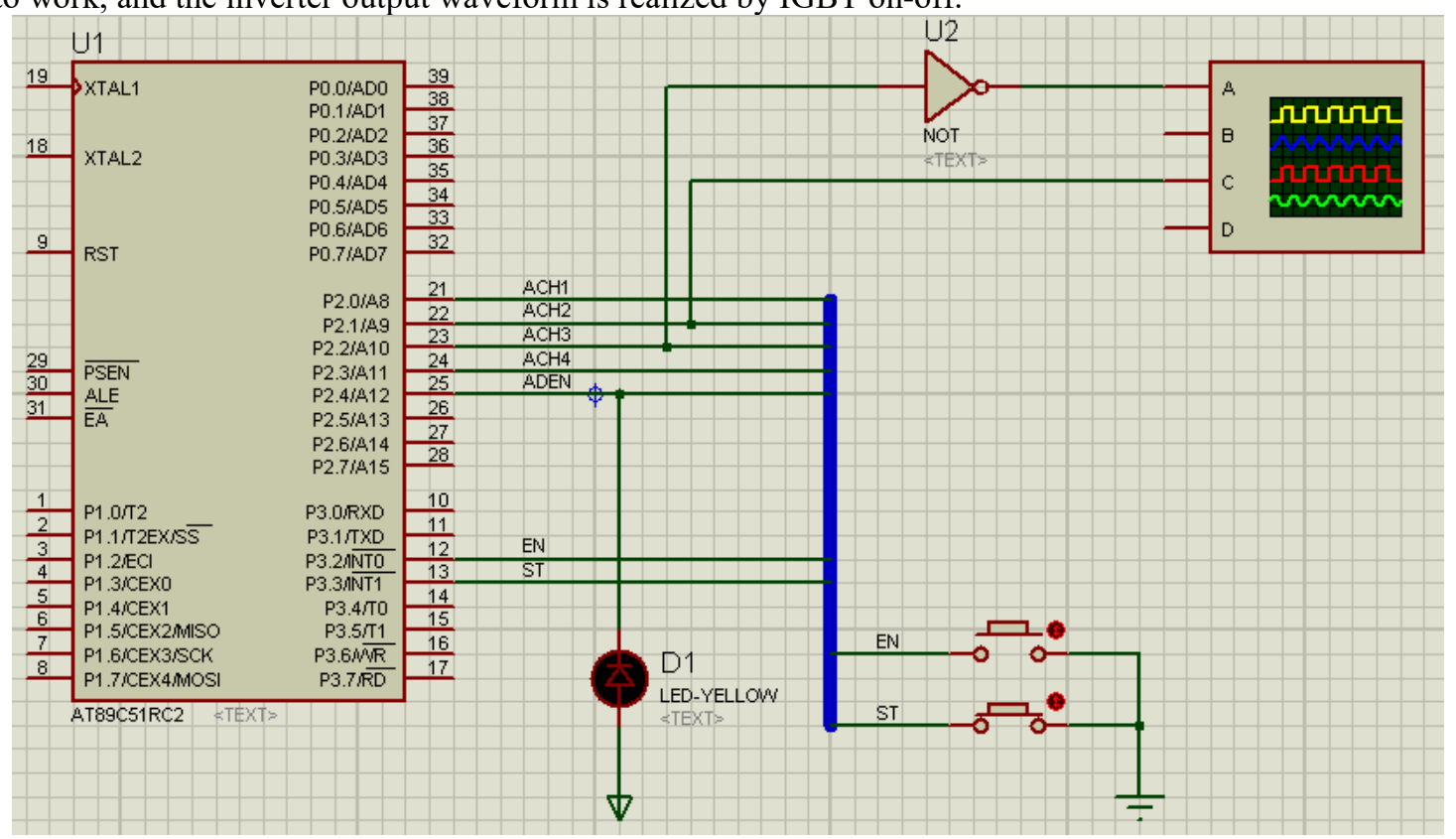

Figure 12: SPWM signal simulation diagram of inverter part

When ST is closed, D1 is on and inverter output to AC 220V. When EN is closed, the inverter starts to work. The waveform of inverter signal simulation and debugging is shown in Figure 13, which is the equivalent sine wave output. 


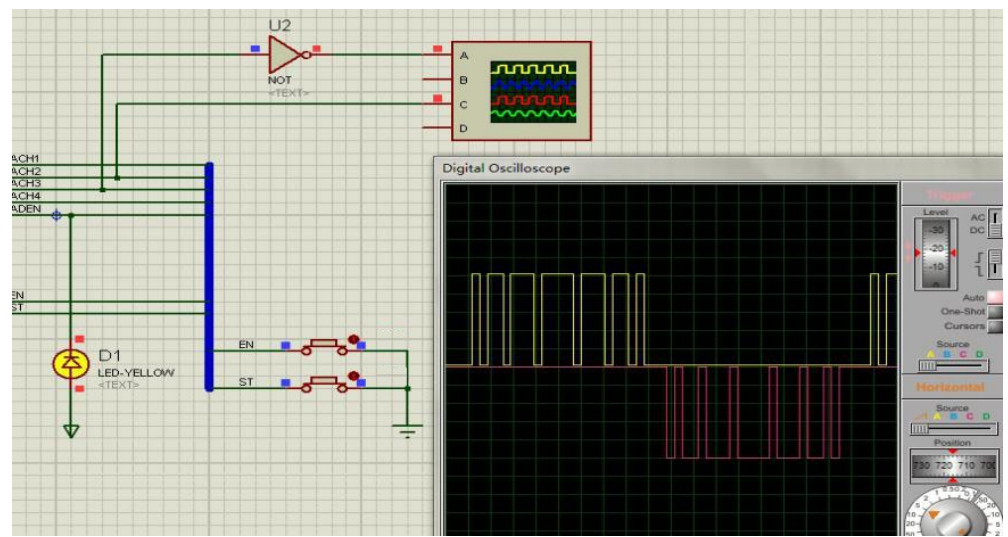

Figure 13: Simulation and debugging of inverter

\section{Conclusion}

In this paper, fuzzy control is applied to MPPT control of photovoltaic system. In order to reduce the vibration of the system at the maximum power point, a MPPT control algorithm based on fuzzy variable step size is proposed. The improved MPPT algorithm improves the tracking speed and stability of photovoltaic system to a certain extent, shortens the tracking time of MPPT, reduces the oscillation amplitude of output voltage and output power curve of photovoltaic system, and reduces the power loss of photovoltaic system.The hardware design and software design of small photovoltaic power generation system are carried out. Finally, the equivalent sine wave output of AC $220 \mathrm{~V}$ is realized, and the solar panel can work near the maximum power point. The simulation and hardware experiment results show that compared with other traditional algorithms, the algorithm proposed in this paper has better tracking accuracy, rapidity and stability under different external conditions.

\section{Acknowledgments}

This works was supported by the Jilin provincial development and reform commission (Grant: 2018C035-1), Jilin provincial science and technology innovation talents \& team project (Grant: 20190101018JH), and the Education Department of Jilin Province (Grant JJKH20200044KJ).

\section{References}

[1] LIU Cheng, WANG Tian-yu, QU Yong-yin, et al.Wind Resources Analysis and Site Selection of Wind Farm.Acta Energiae Solaris Sinica, 37(11):2835-2842,2016.

[2] ZHU Shijia, SHAO Hua, FAN Huicong, et al.Maximum Power Point Tracking Strategy of Photovoltaic System under Variable Environment Based on Optimal Voltage Control.Proceedings of the CSUEPSA,31(12):1-8,2019.

[3] HANG Fenghai, YANG Wei, ZHU Wenyan.Analysis and improvement of MPPT disturbance observer method for PV system.Power System Protection and Control, 42(9):110-114, 2014.

[4] CHEN Xia, ZHAO Fengyin, WANG Aiyu, et al.Research of Maximum Power Point Tracking Algorithms of Photovoltaic Arrays Based on the Improved Disturbance of Observer Method.Electric Drive,47(3):6669+77,2017.

[5] Harrag A, Messalti S. Variable step size modified P\&O MPPT algorithm using GA- based hybrid offline/online PID controller. Renewable \& Sustainable Energy Reviews, 49:1247-1260, 2015.

[6] YU Yunjun, ZHANG Xiang, WANG Shisheng, et al.Review of incremental conductance method for photovoltaic power generation MPPT.Power Supply Technology, 38(12):2440-2444, 2014.

[7] GAO Song, LUO Hao, HE Ning, et al.Research on a new method for variable step size INC based on maximum power point tracking.Electric Drive, 45(2):16-19+49, 2015.

[8] ZHANG Xiaoqiang, LIU Yigang, ZOU Yingquan, et al. An Enhanced Photovoltaic Mppt Approach Based on Adaptive Neural Network Control.Acta Energiae Solaris Sinica, 40(11):3095-3102, 2019.

[9] Dounis A I, Kofinas P, Papadakis G, et al. A direct adaptive neural control for maximum power point tracking of photovoltaic system. Solar Energy, 115:145-165, 2015. 
[10] YANG Tong-guang, GUI Wei-hua.Application of Neural Network Backstepping Control in Maximum Power Point Tracking of Photovoltaic System.Acta Energiae Solaris Sinica,37(12):3030-3036,2016.

[11] LIU Cheng, LI Ze-qing, WANG Tian-yu, et al.Grid-connected Inverter Based on Fuzzy Proportional QuasiPR Control.Journal of Beihua University (Natural Science Edition),16(05):693-696,2015.

[12] Shahriar Farajdadian, S.M. Hassan Hosseini.Optimization of fuzzy-based MPPT controller via metaheuristic techniques for stand-alone PV systems.International Journal of Hydrogen Energy, 44(47):25457-25472. 2019.

[13] M. Bechouat, M. Sedraoui, C.-E. Feraga,et al.Modeling and Fuzzy MPPT Controller Design for Photovoltaic Module Equipped with a Closed-Loop Cooling System.Journal of Electronic Materials,48(9):5471$5480,2019$.

[14] ZHAN Junnan, BAI Di.Improved MPPT Algorithm Based on Fuzzy PI Controller.Distributed Energy, 4(4):30-34, 2019.

[15] Mohammad Junaid Khan, Lini Mathew.Fuzzy logic controller-based MPPT for hybrid photovoltaic/wind/fuel cell power system. Neural Computing and Applications,31(10):6331-6344,2019. 